\title{
Streptococcus constellatus: agente etiológico asociado en empiema pleural
}

\author{
José Antonio Díaz Peromingo, Joaquín Sánchez Leira, \\ Florinda G arcía Suárez, Emilio Padín Paz, \\ Juan Saborido Froján. \\ Streptococcus constellatus \\ as a causative agent of empyema. \\ Report of one case
}

\begin{abstract}
Streptococcus constellatus is a commensal microorganism in man but may cause infections in different locations. We report a 59 years old male with severe sequelae of a previous cerebrovascular accident that consulted in the emergency room for fever of 15 days of evolution. A right empyema was diagnosed. The bacteriological culture of the effusion disclosed the presence of Streptococcus constellatus and two anaerobic strains (Prevotella intermedia and Fusobacterium urealyticus). The patient was treated with a pleural drainage and received ceftriaxone and clindamycin during six weeks. He was discharged in good conditions and is asymptomatic after eight months of follow up (Rev Méd Chile 2006; 134: 1030-2).
\end{abstract}

(Key words: Ceftriaxone; Empyema, pleural; Streptococcus constellatus)

Recibido el 3 de noviembre, 2005. Aceptado el 20 de enero, 2006.

Servicio de Medicina Interna, Hospital da Barbanza, Riveira A Coruña, España.

$\mathrm{E}^{1}$ empiema pleural causado por Streptococcus constellatus, si bien sigue siendo una infección rara, probablemente está aumentando en la actualidad. La realización de maniobras diagnósticas, tanto digestivas como respiratorias, por ejemplo broncoscopia o endoscopia digestiva alta, y la presencia cada vez mayor de enfermedades crónicas subyacentes, puede contribuir a este aumento

Correspondencia a: José Antonio Díaz Peromingo. C/ República Argentina ํㅡㄹ, 3ํA. 15702. Santiago de Compostela. España. E mail: jadiazperomingo@mundo-r.com paulatino $^{1}$. En ocasiones, estas infecciones pueden producirse incluso sin la concurrencia de una maniobra endoscópica previa, sobre todo si existe una patología grave subyacente. A continuación presentamos el caso de un paciente con secuelas graves de una enfermedad neurológica previa y empiema pleural causado por Streptococcus constellatus asociado a anaerobios.

\section{CASO CLÍNICO}

Varón de 59 años de edad con el antecedente de accidente cerebrovascular aterotrombótico en te- 
rritorio de la arteria cerebral media izquierda, con afasia sensitivo-motora y hemiparesia derecha residuales que fue llevado a Urgencias por un cuadro de 15 días de evolución, consistente en fiebre de predominio vespertino y deterioro del estado general, con disminución de la ingesta oral. En la exploración física destacaba fiebre de $39^{\circ} \mathrm{C}$, pulso $105 \mathrm{lpm}$, TA 100/60 mmHg y disminución del murmullo pulmonar en hemitórax derecho. Analíticamente, presentaba un hemograma con 18.900 leucocitos/ $\mathrm{mm}^{3}$ (8\% baciliformes), leve anemia con $\mathrm{Hb} 11,9 \mathrm{~g} / \mathrm{L}$ (normal 13-15,5 g/L), normocítica y normocrómica, y plaquetas $480.000 / \mathrm{mm}^{3}$. La coagulación y bioquímica sanguínea eran normales. La radiografía de tórax mostró la existencia de derrame pleural submasivo derecho. Se realizó ecografía abdominal que no mostró alteraciones significativas. El análisis del líquido pleural evidenció un líquido con aspecto de pus y olor pútrido, bioquímicamente compatible con exudado purulento con un $\mathrm{pH}$ de 6,98, glucosa $17 \mathrm{mg} / \mathrm{dl}$, proteínas 4,6 $\mathrm{mg} / \mathrm{dl}$, LDH 427 UI/L, ADA 19 (normal <50) y estudio citológico negativo para malignidad. El cultivo fue positivo para Streptococcus constellatus y especies de anaerobios (Prevotella intermedia y Fusobacterium urealyticus). La tinción de auramina en el líquido pleural y el cultivo en medio de Löwenstein fueron negativos. Los hemocultivos fueron, asimismo, negativos. Se inició tratamiento con Ceftriaxona ( $2 \mathrm{gr} /$ día) y Clindamicina $(600 \mathrm{mg} / 8 \mathrm{~h}$ ) más colocación de tubo de drenaje pleural. El drenaje pleural se mantuvo durante 3 semanas, retirándose cuando el débito fue menor de 50 cc diarios durante 3 días consecutivos. Se trató con antibióticos durante 6 semanas y la evolución fue lenta pero progresivamente favorable, con completa resolución del empiema en el momento del alta, sin necesidad de utilizar fibrinolisis intrapleural. Tras un seguimiento de 8 meses el enfermo se encontraba asintomático y en su situación basal. La radiografía de tórax no mostró alteraciones pleuropulmonares residuales.

\section{DisCUSIÓN}

El grupo de estreptococos denominados previamente S milleri o Sgrupo anginosus-millerim, que incluye estreptococos hemolíticos y no hemolíticos, ha tenido históricamente una clasificación confusa y cambiante a lo largo del tiempo. Actualmente se reconocen como Streptococcus grupo anginosus. Este grupo incluye tres especies muy relacionadas: Sconstellatus, Sintermedius y S anginosus. De acuerdo a la antigua clasificación de Lancefield, poseen los antígenos de grupo $\mathrm{F}$ y $\mathrm{G}$ principalmente, pero también pueden presentar los antígenos A y C. Dado que la clasificación en base a la aglutinación del carbohidrato $\mathrm{C}$ puede ser errónea, la identificación de estas especies es compleja y requiere de numerosas pruebas bioquímicas y fisiológicas, muchas veces no disponibles en un laboratorio clínico, llegando sólo al diagnóstico microbiológico de grupo anginosus. En nuestro caso, el diagnóstico se realizó en un principio en base a los resultados de ciertas pruebas bioquímicas (negatividad para beta-galactosidasa, beta-glucosidasa, manitol, lactosa, peróxido de hidrógeno y rafinosa con positividad para alfa-glucosidasa) y fue posteriormente confirmado mediante la amplificación por PCR (reacción en cadena de la polimerasa) del ARN ribosómico y posterior utilización de sondas de hibridación específicas ${ }^{2,3}$. A nivel clínico, Streptococcus constellatus es un comensal habitual de boca, garganta, tracto gastrointestinal y vagina. Como comensal orofaríngeo no suele provocar infecciones, pero en el seno de infecciones agudas de otro foco, cirugías o manipulaciones de la vía digestiva como la gastroscopia o de la vía respiratoria como la broncoscopia puede ser la causa de abscesos dentales, del sistema nervioso central, cavidad abdominal, endocarditis, empiema pleural y absceso pulmonar ${ }^{4,5}$. El compromiso pulmonar y pleural, constituye menos de $25 \%$ del total de infecciones causadas por este microorganismo ${ }^{6}$. Actualmente, a S constellatus subsp pharyngis subs nov se le reconoce como agente etiológico de amigdalitis y faringitis ${ }^{7}$. Habitualmente, los estreptococos colonizantes de la boca y del tracto respiratorio superior se suelen considerar como comensales sin relevancia patógena. La importancia en el desarrollo de infecciones respiratorias es creciente y, en especial, la existencia de coinfección con bacterias anaerobias con efecto sinérgico ${ }^{8}$, si bien se ha comunicado previamente la génesis de empiema pleural con cultivo puro de Streptococcus constellatus ${ }^{5}$. En cuanto a la coin- 
fección, se ha sugerido que al menos un anaerobio, como es Prevotella intermedia, puede actuar junto a $\mathrm{S}$ constellatus en la producción de infecciones pulmonares, al estimular el crecimiento de este último y suprimir la actividad bactericida del huésped $^{9}$ como podría ser el caso de nuestro paciente. En una serie japonesa, la presencia de enfermedades subyacentes moderadas o severas se observó en $86,7 \%$ de los pacientes con infecciones agudas del tracto respiratorio superior asociadas a bacterias del grupo denominado Streptococcus anginosus. De ellos, sólo 13,3\% eran portadores de enfermedades del sistema nervioso central. De los 3 estreptococos que constituyen el grupo anginosus, S constellatus fue el más frecuentemente aislado en esta serie ${ }^{10}$. Las bacteremias por microorganismos pertenecientes al grupo de Streptococcus anginosus (ex milleri) son infrecuentes y se suelen asociar fundamentalmente a un foco de sepsis intraabdominal, siendo

\section{REFERENCIAS}

1. Ortiz J, Barbancho S, Mostaza J. Mediastinitis y empiema pleural por Streptococcus constellatus. Arch Bronconeumol 2004; 40: 602-3.

2. Ruoff KL, Whiley RA, Brighton D. Streptococcus, In: P. R. Murray, E. J. Baron, J. H. Jorgensen, M. A. Pfaller, R. H. Yolken (ed). Manual of Clinical Microbiology, $8^{\text {th }}$ ed. American Society of Microbiology, Washington DC. 2003; 405-21.

3. Caro GD, Riedel IK, García PC. Caracterización clínica y microbiológica de las infecciones causadas por Streptococus grupo anginosus. Rev Chil Infect 2004; 21: 254-60.

4. Shinzato T, Saito A. The Streptococcus milleri group as a cause of pulmonary infections. Clin Infect Dis 1995; 21 (Suppl 3): 238-43.

5. Mediavilia J, Arroyo A, López M, Cuesta I, Mateas F. Empiema masivo por Streptococcus constellatus. An Med Interna 1997; 14: 488-9.

6. Molna JM, Leport C, Bure A, Wolff M, Michon C, VILDE JL Clinical and bacterial features of infections caused by Streptococcus milleri. Scan J Infect Dis 1991; 23: 659-66. aproximadamente un tercio, las debidas a focos pulmonares como empiema o absceso ${ }^{11}$. En la literatura en lengua española, sólo hemos encontrado un caso de mediastinitis y empiema pleural por S constellatus en un paciente que no había sufrido manipulación de la vía digestiva ni respiratoria y otro de empiema masivo en un paciente con secuelas neurológicas de un hematoma protuberancial previo ${ }^{1,5}$. El tratamiento fundamental de las infecciones por Streptocuccus constellatus sigue siendo la penicilina o las cefalosporinas de $3^{\text {a }}$ generación, asociando fármacos con actividad anaerobicida, si coexiste infección por anaerobios como en el caso de nuestro paciente. Creemos que la comunicación de casos como el presente puede contribuir a dilucidar la patogenia de esta infección, identificar sus factores de riesgo y tratar de prevenir su ocurrencia al reconocer a aquellos pacientes con patología de base susceptible de facilitar su aparición.

7. Whiley RA, Hall LM, Hardie JM, Beighton D. A study of small-colony, beta-haemolytic, Lancefield group $\mathrm{C}$ streptococci within the anginosus group: description of Streptococcus constellatus subsp. pharyngis subsp. nov., associated with the human throat and pharyngitis. Int J Syst Bacteriol 1999; 49: 1443-9.

8. Porta G, Rodríguez-Carballeira M, Gómez L, Salavert M, Freixas N, Xercavins M et al. Thoracic infection caused by Streptococcus milleri. Eur Respir J 1998; 12: 357-62.

9. Shinzato T, Saito A. A mechanism of pathogenicity of «Streptococcus milleri group» in pulmonary infection: synergy with an anaerobe. J Med Microbiol 1994; 40: 118-23.

10. Fujiki R, Kawayama T, Rikimaru T, Oizumi K. A three-year review of acute respiratory tract infections caused by Streptococcus milleri group. Kansenshogaku Zasshi 2002; 76: 174-9.

11. Weightman NC, Barnham MR, Dove M. Streptococcus milleri group bacteriemia in North Yorkshire, England (1989-2000). Indian J Med Res 2004; 119 (Suppl): 164-7. 